Revista de Economia Política, vol. 29, $n^{\circ} 1$ (113), pp. 82-91, janeiro-março/2009

\title{
Mudança estrutural, desenvolvimento institucional e crescimento econômico sustentado: um comentário sobre a experiência irlandesa
}

\author{
FERNANDA CARDOSO \\ DANIELA CORRÊA \\ GILBERTO TADEU LIMA*
}

Structural change, institutional development and sustained economic growth: a comment on the Irish experience. It is discussed the recent Irish experience of sustained economic growth, in which a social pact, the entry in the European Union and the opening of the economy have all played a paramount role. Some remarks on the sustainability of such an experience are also made.

Keywords: structural change; institutional development; economic growth.

JEL Classification: E65; F43; O52.

\section{INTRODUÇÃO}

O grande destaque europeu nas últimas décadas em termos de crescimento foi a Irlanda, experiência que teve como elemento fundamental a celebração de um pacto social no final dos anos 1980 . O sucesso desse pacto social, somado à abertura da economia para a Europa, à ruptura com a libra esterlina, às políticas de atração de investimento direto externo (IDE), aos avanços tecnológicos e a uma melhor organização industrial, produziram, em pouco tempo, uma economia com índices elevados de crescimento, o que lhe rendeu o apelido de "tigre celta".

\footnotetext{
* Respectivamente, Economista pela Faculdade de Economia e Administração da Universidade de São Paulo - FEA-USP e Doutoranda pelo IPE-FEA-USP. E-mail fgc13@uol.com.br; Economista pela FEAUSP e Mestranda em Economia pelo IE-UFRJ. E-mail: daniela_gmc@yahoo.com.br; e Professor do Departamento de Economia da FEA-USP, que agradece ao CNPq por bolsa de pesquisa. E-mail: giltadeu@usp.br. Cabem agradecimentos - acompanhados das isenções usuais - a dois pareceristas por úteis comentários. Submetido: Agosto 2006; Aprovado: Fevereiro 2007.
} 
Entre 1980 e 1990, a taxa média de crescimento anual na Irlanda foi de 3,2\%, enquanto a média européia era de $2,4 \%$. Entre 1990 e 2003, quando a média de crescimento anual européia encolheu para 2,0\%, a taxa irlandesa foi de $7,7 \%$, a segunda maior em todo o mundo, atrás apenas da chinesa. Antes do boom, a Irlanda já havia desenvolvido alguns dos pré-requisitos para o crescimento rápido: uma força de trabalho subempregada; um estoque de emigrantes com potencial de retorno, na eventualidade de melhores perspectivas de emprego; um amplo abastecimento energético; uma rede de transporte subutilizada; e um serviço público eficiente. Outros fatores que contribuíram para o crescimento econômico incluem a efetividade das instituições relacionadas ao estabelecimento de leis e a profundidade e eficiência do sistema financeiro, além de fatores culturais, como a língua inglesa nativa.

A Tabela 1 indica e evolução do produto per capita da Irlanda em relação aos 25 países componentes da União Européia (UE) e à zona do euro na última década e a variação anual do produto real. $O$ caso irlandês revela um desempenho bastante acima da média dos demais países do conjunto, com um diferencial crescente a partir de meados dos anos 1990. Em relação à variação anual do PIB real per capita, verifica-se que o desempenho do país esteve sempre acima dos índices para a média da UE.

Tabela 1

Irlanda: Indicadores do PIB

\begin{tabular}{|c|c|c|c|c|c|c|c|c|c|c|c|}
\hline & & 1997 & 1998 & 1999 & 2000 & 2001 & 2002 & 2003 & 2004 & 2005 & 2006 \\
\hline PIB per capita & $(\mathrm{UE}-25=100)$ & 112,3 & 116,8 & 121,8 & 126,1 & 128,5 & 132,3 & 134,4 & 135,7 & 138,9 & $139,2^{*}$ \\
\hline \multirow{2}{*}{$\begin{array}{l}\text { Crescimento } \\
\text { do PIB real (\%) }\end{array}$} & UE-25 & 2,7 & 2,9 & 3,0 & 3,9 & 2,0 & 1,2 & 1,3 & 2,4 & 1,7 & $2,8^{*}$ \\
\hline & Irlanda & 11,7 & 8,5 & 10,7 & 9,4 & 5,8 & 6,0 & 4,3 & 4,3 & 5,5 & $5,3^{*}$ \\
\hline
\end{tabular}

* previsão

Fonte: Eurostat.

Além desta introdução, o presente artigo está dividido em duas seções. $\mathrm{Na}$ primeira são avaliados alguns potenciais determinantes do êxito econômico do país, destacando fatores como a utilização dos fundos estruturais da UE e o pacto social, entre outros. Na terceira seção são avaliados os resultados e as perspectivas futuras para a economia irlandesa.

\section{DETERMINANTES DO SUCESSO ECONÔMICO DO “TIGRE CELTA”}

A taxa média de crescimento anual entre 1990 e 2003 foi de 7,7\%, configurando a segunda maior média do período, atrás apenas da chinesa. Entre 1980 e 1990, a taxa média anual de crescimento do país havia sido apenas modesta, $3,2 \%$, o que justifica o interesse sobre as transformações que teriam permitido salto tão grande no padrão de crescimento do país.

No final dos anos 1980 a Irlanda apresentava uma delicada situação fiscal - a 
dívida pública em relação ao produto era de cerca de $120 \%$-, além de sério problema de desemprego, forte ressurgimento da emigração, baixo crescimento econômico e um padrão de vida em processo de deterioração. Uma peça central para a reversão desse quadro foi a celebração de um pacto social - Program for National Recovery (1987-1990) - que removeu o ressentimento popular com relação ao debate macroeconômico e resultou em relações de trabalho estáveis. Em adição ao pacto social, outros fatores desempenharam importantes papéis, entre os quais, a abertura para a Europa, a ruptura com a libra esterlina, o IDE, as mudanças tecnológicas, a reorganização industrial e uma crescente atenção ao papel da informação.

No final dos anos 1980, a estrutura industrial mudava significativamente, na medida em que as multinacionais se moviam do modelo de produção em massa para o estilo de produção caracterizado por maior flexibilidade. Tal mudança levou as filiais a adotarem modelos mais flexíveis e integrados à economia local. Particularmente, a nova tecnologia reduziu os custos de transporte e de comunicação, reduzindo também a desvantagem irlandesa de ser uma economia isolada. Nesse novo contexto, o IDE passou a fluir para o país, que atraiu algumas companhias pioneiras que visavam um rápido crescimento global, como por exemplo, a Intel e a Microsoft.

A grande magnitude da dívida pública no final dos anos 1980 explicitou a importância do setor exportador para a promoção do crescimento do país. Isto, por sua vez, requeria uma economia competitiva sustentada por um investimento adequado tanto em qualidade como em quantidade. Com a situação macroeconômica essencialmente fora de debate e com as relações trabalhistas estáveis, o foco das políticas públicas se voltou para o crescimento (McCarthy, 2001). Como ressalta Ó Gráda (2002), porém, a Irlanda já havia desenvolvido antes do boom alguns dos pré-requisitos para o crescimento rápido: uma força de trabalho subempregada; um estoque de emigrantes com potencial de retorno, dadas as melhores perspectivas de emprego; um amplo abastecimento energético; uma rede de transporte subutilizada; um serviço público relativamente eficiente.

Cabe enfatizar ainda algumas características particulares da economia irlandesa, como o elevado grau de abertura econômica - a economia do país é uma das mais globalizadas do mundo, com mais da metade de seus setores produtivo e financeiro sob comando estrangeiro - e uma elevada propensão à emigração - durante o boom de crescimento dos anos 1990, tal propensão foi substituída por uma alta taxa de imigração. Para Honohan e Walsh (2002), tais aspectos da abertura irlandesa ao restante do mundo contribuíram sobremaneira para a habilidade de sua economia em viabilizar um acelerado crescimento do emprego. Outros fatores que contribuíram para o crescimento incluem a efetividade de instituições relacionadas ao estabelecimento de leis, a qualidade da administração pública e a profundidade e eficiência do sistema financeiro.

Podem ainda ser mencionados fatores culturais, como a familiaridade dos investidores americanos (os maiores investidores no país) com relação à língua e aos sistemas administrativos legais irlandeses, além da capacidade da economia de 
reagir às circunstâncias mutantes, como a reconhecida aptidão irlandesa de lidar com mudanças tecnológicas. Além disso, uma força de trabalho relativamente jovem e crescente, com nível educacional alto, era o fator ideal a ser empregado no processo produtivo caracterizado por altos níveis tecnológicos. Entre os fatores catalíticos, destacam-se o fluxo de fundos estruturais da UE, as desvalorizações cambiais de 1986 e 1993 e a promoção revitalizada do turismo e do IDE (Honohan e Walsh, 2002).

\section{Adesão à UE e o acesso a fundos estruturais}

A adesão à Comunidade Econômica Européia em 1973 impôs diretrizes claras para a condução da economia, de modo a torná-la mais eficiente. Sob o novo regime de livre-comércio, as exportações cresceram expressivamente, ao mesmo tempo em que a composição e a direção das exportações mudavam de bens primários para manufaturados (McCarthy, 2001).

O setor agrícola beneficiou-se das transferências da CAP - Common Agricultural Policy, que buscava sustentar o preço dos bens agrícolas acima do preço vigente nos mercados internacionais, através do fechamento de mercados. A queda do emprego agrícola não foi acompanhada por um grande problema social, pois a maior parte da mão-de-obra egressa desse setor foi absorvida nos demais. Essa absorção foi particularmente favorecida nos anos 1990, graças ao crescimento nos outros setores, com destaque para o de serviços, ao mesmo tempo em que se adotava uma política ativa para direcionar o desemprego (McCarthy, 2001). A Irlanda teve acesso a outros três fundos: ERDF - European Regional Development Fund - destinado a dar assistência para o desenvolvimento das regiões mais pobres; ESF - European Social Fund; e EAGGF - Guidance Section of the CAP funds. O objetivo desses fundos era tornar o país apto a competir no mercado único, sendo seus recursos direcionados principalmente para o desenvolvimento das infra-estruturas física e social.

\section{Pacto social}

A celebração do pacto social em 1987 ficou por conta do NESC (National Economic and Social Council), cujo corpo consultivo era composto por representantes de empregadores e sindicatos, do setor agrícola e da sociedade civil. $\mathrm{O}$ acordo cobria um amplo espectro de questões relevantes para todos os grupos da sociedade e, inicialmente, a meta principal era estabelecer uma fórmula que modelaria os acordos salariais nos três anos seguintes, provendo pequenos aumentos anuais, e estabelecendo relações trabalhistas pacíficas no período. Em troca, o governo concordou em reformar o sistema tributário em favor dos trabalhadores. Esse último aspecto foi particularmente crucial para o pacto social irlandês, em uma fase em que o estado de bem-estar social estava sob ameaça (Ó Gráda, 2002).

$\mathrm{Na}$ avaliação de Honohan e Walsh (2002), os acordos sociais refletiam a determinação de deixar de lado, ao menos temporariamente, o antagonismo de clas- 
ses em favor de um esforço conjunto para remover as barreiras ao crescimento do emprego. Ao mesmo tempo, a precondição mais importante para a adoção desses acordos era o reconhecimento geral de que a crise nas finanças públicas deveria ser resolvida e que a solução para a redução do desemprego não poderia ser encontrada na expansão fiscal.

\section{Políticas fiscal e cambial}

A partir da segunda metade da década de 1980 houve um rápido progresso nas contas fiscais, para o qual o ano de 1987 foi decisivo. Não somente o marcado arrocho da política, como a velocidade com que a tomada de empréstimos e a taxa de dívida reagiram foram surpreendentes. Entretanto, o papel fundamental das condições externas favoráveis não pode ser negligenciado. A partir de 1988-89 a situação da dívida havia sido claramente controlada, criando condições propícias para a retomada do investimento (Honohan e Walsh, 2002).

As medidas fiscais adotadas em 1987 tinham caráter convencional: congelamento temporário na contratação do setor público, combinado com choques nos gastos públicos. As condições favoráveis ajudaram a colocar em funcionamento os estabilizadores automáticos, como a reversão do processo emigratório e uma melhora na demanda doméstica por trabalho, que diminuíram a taxa de desemprego. A queda na taxa de juros também contribuiu positivamente, e quando a relação dívida/produto começou a cair em 1987, o feedback positivo tornou-se cumulativo. A atividade econômica começou a ganhar força no final dos anos 1980, e a arrecadação aumentou, permitindo ao governo uma maior redução nas taxas de juros.

Com a estabilização fiscal e a inflação permanentemente baixa, a manutenção da confiança tornou-se uma das principais metas do governo. A receita fiscal também foi beneficiada pelo recebimento de concessões estruturais substancialmente expandidas da receita da UE depois de 1988. Isto veio em um momento crucial, uma vez que, ao utilizar esses fundos, o governo pôde financiar uma série de projetos de infra-estrutura sem ameaçar a inicialmente frágil recuperação das contas públicas. De maneira geral, a correção fiscal bem-sucedida, a taxa de câmbio competitiva, e uma concomitante queda nas taxas de juros forneceram as condições econômicas necessárias para o crescimento.

\section{Mão-de-obra e educação}

Em 1967, a educação de ensino médio tornou-se gratuita no país, e em 1968 foram introduzidos esquemas de incentivo ao ensino superior, o que fez crescer expressivamente a participação educacional nas décadas seguintes, contribuindo sobremaneira para a formação da força de trabalho altamente qualificada que ajudou a impulsionar o crescimento econômico dos anos 1990 (McCarthy, 2001). $\mathrm{Na}$ avaliação de Honohan e Walsh (2002), o aspecto mais notável do bom desempenho irlandês foi o crescimento na participação da força de trabalho, o que, por 
sua vez, é em parte função das próprias tendências demográficas, e em parte, de uma considerável redução na taxa de desemprego.

A Tabela 2 indica a variação anual no emprego na Irlanda, em comparação com os demais países da UE, e a produtividade por trabalhador empregado. A taxa de variação anual da população empregada no país foi sempre positiva no período analisado, e bastante superior à média dos demais países da UE. A produtividade por trabalhador também revela índices para o país acima da média da UE, corroborando os efeitos do trabalho sobre o crescimento.

Tabela 2

Emprego e produtividade - Indicadores Comparativos

\begin{tabular}{|l|c|c|c|c|c|c|c|c|c|c|}
\hline \multicolumn{2}{|c|}{} & 1997 & 1998 & 1999 & 2000 & 2001 & 2002 & 2003 & 2004 & 2005 \\
\hline $\begin{array}{l}\text { Variação anual na } \\
\text { população empregada (\%) }\end{array}$ & UE-25 & 1,1 & 1,6 & 1,3 & 1,6 & 1,3 & 0,5 & 0,4 & 0,6 & 0,8 \\
\cline { 2 - 11 } & Irlanda & 5,6 & 8,6 & 6,2 & 4,6 & 3,0 & 1,8 & 2,0 & 3,1 & 4,6 \\
\hline $\begin{array}{l}\text { Produtividade por } \\
\text { trabalhador empregado } \\
\text { (UE-25 = 100) }\end{array}$ & Zona do euro & 122,2 & 120,2 & 120,4 & 122,4 & 123,8 & 127,5 & 128,9 & 128,7 & 129,3 \\
\cline { 2 - 11 } & Irlanda & 112 & 111,6 & 110,5 & 109,5 & 108,2 & 107,3 & 106,9 & 106,2 & 106,1 \\
\hline
\end{tabular}

Fonte: Eurostat.

\section{Importância do investimento direto estrangeiro}

Depois de experimentar um crescimento errático dos anos 1960 até meados dos anos 1980, a economia irlandesa começou a se destacar. O bom desempenho passou a atrair o IDE, o que representou uma dinâmica de crescimento adicional. Estima-se que, a partir do final da década de 1970, a Irlanda teria passado a receber participações crescentes do investimento direto em manufatura dos Estados Unidos na Europa.

Os atrativos para o IDE correspondem não somente às baixas taxas de juros, mas também garantia de assistência, isenções fiscais, liberdade para repatriação de lucros, livre acesso aos demais países da Comunidade Européia, além dos fatores acima mencionados. Apesar da rápida redução no desemprego, do progresso fiscal e das notáveis taxas de crescimento - principalmente a partir dos anos 1990 - refletirem uma grande melhora na competitividade, essas melhorias também se devem às condições externas mais favoráveis. $\mathrm{O}$ ímpeto externo proveniente do IDE, principalmente dos EUA, exerceu, por sua vez, um impacto multidimensional sobre a performance econômica irlandesa.

Segundo Honohan e Walsh (2002), uma parcela muito grande das empresas atraídas por esses incentivos vinha de indústrias bem estabelecidas, interessadas em aproveitar as vantagens fiscais que o país oferecia. Conforme os autores, entre as economias avançadas, a Irlanda é o país que apresenta os menores impostos sobre atividades e rendimentos das corporações. Em muitos casos, afirmam, os altos lucros registrados pelas filiais irlandesas não correspondem às atividades conduzidas no país, como será destacado adiante.

Inicialmente, o grande crescimento do produto, e especialmente das exportações, não foi acompanhado por grandes avanços no problema do desemprego. 
Porém, ao longo do tempo, as novas empresas construíram laços com os fornecedores locais, fortalecidos nos anos seguintes. Dado o tamanho reduzido do mercado doméstico, a produção dessas multinacionais era altamente dependente da demanda externa e, conseqüentemente, sensível ao estado da economia global. Em um clima global favorável, especialmente para o setor tecnológico, tal estratégia de IDE era bastante atrativa. Em adição ao impacto direto no emprego e nas exportações, essa estratégia auxiliou no estabelecimento de ligações entre muitas companhias domésticas e também no fortalecimento das habilidades empresariais (McCarthy, 2001).

Uma proporção considerável do emprego no setor manufatureiro de propriedade estrangeira está alocada em setores de alta tecnologia, de maquinarias e de engenharia elétrica. Como conseqüência, a média salarial na indústria estrangeira é aproximadamente $25 \%$ maior do que a média da indústria doméstica. Além disso, uma vez que a maior parte da indústria estrangeira é representada por setores de alta tecnologia, pode-se esperar que seja desviada para tais setores uma quantidade substancial de investimento em P\&D.

A natureza e a extensão das interações do país com a economia mundial se manifestam de duas formas particulares. Primeiramente, uma grande parte da indústria irlandesa se constitui de filiais de multinacionais e, em segundo lugar, a indústria manufatureira do país está agora quase totalmente orientada para exportação devido ao tamanho reduzido do mercado doméstico. Assim, a produção de comercializáveis na Irlanda é determinada por dois fatores principais: a demanda mundial e o custo de competitividade internacional irlandês (Bradley e Barry, 1997).

\section{Exportações e crescimento}

As indústrias de alta tecnologia - geralmente de capital estrangeiro - dos setores farmacêutico, de engenharia elétrica e de processamento de dados são largamente orientadas para a exportação, desfrutam de altos níveis de produtividade e são responsáveis por grande parcela do montante exportado comparativamente à indústria doméstica. Na avaliação de Doyle (2001), o forte desempenho da produtividade das empresas nos setores dominados pelo capital estrangeiro pode, na realidade, refletir o sucesso da baixa carga tributária sobre as empresas - utilizada para atrair o investimento direto para o país - e não necessariamente aumentos na produtividade das próprias indústrias. Através das transferências entre as filiais das multinacionais, as empresas baixam artificialmente o preço dos insumos que entram na Irlanda e aumentam o valor da produção exportada pelo país, de modo que consigam fazer incidir o máximo possível de impostos sobre os lucros dentro do país, onde as taxas são menores.

Por outro lado, conforme observado por Doyle (2001), resultados de testes empíricos sobre a relação entre a exportação e o crescimento da produção na Irlanda revelam que há uma causalidade bidirecional entre esses dois fatores. Podese dizer, então, que há um ciclo virtuoso de crescimento e exportações: qualquer 
crescimento na produção irlandesa tem efeitos de retroalimentação que levam à expansão da exportação. De fato, como demonstram os dados da Tabela 3, os índices de exportação e importação da economia irlandesa são extremamente elevados, configurando uma economia com elevado grau de abertura, como já mencionado anteriormente. A participação das exportações de alta tecnologia no total também merece destaque: quase $40 \%$ das exportações de manufaturados correspondem a produtos de alta tecnologia. Os demais indicadores da tabela apontam para uma economia bastante saudável.

Tabela 3

Irlanda - Indicadores Selecionados

\begin{tabular}{|l|c|c|c|c|c|}
\hline & 2000 & 2001 & 2002 & $\mathbf{2 0 0 3}$ & 2004 \\
\hline Crescimento anual do PIB (\%) & 9,9 & 6 & 6,1 & 3,7 & 4,9 \\
\hline Exportação de bens e serviços (\% do PIB) & 97,7 & 98,4 & 93,5 & 83,7 & 80,2 \\
\hline Importações de bens e serviços (\% do PIB) & 84,5 & 83,4 & 77 & 68,2 & 64,7 \\
\hline Formação Bruta de Capital (\% do PIB) & 25 & 24 & 23 & 24 & 25 \\
\hline $\begin{array}{l}\text { Exportações de alta tecnologia } \\
\text { (\% exportações de manufaturados) }\end{array}$ & 47,5 & 47,3 & 40,6 & 34,5 & 33,8 \\
\hline Valor adicionado indústria (\% do PIB) & 42,4 & 41,7 & 41,9 & 41 & - \\
\hline Inflação anual - deflator do PIB (\%) & 4,8 & 5,7 & 4,5 & 1,6 & 3,5 \\
\hline
\end{tabular}

Fonte: World Development Indicators database.

\section{Reestruturação financeira e investimento privado}

A maior contribuição para o crescimento da demanda no país, entre o final dos anos 1980 e início da década de 1990, foi dada pela exportação líquida - atribuída tanto ao aumento da competitividade como à formação de capital no setor exportador. A partir da metade da década de 1990, porém, a prosperidade da economia e as baixas taxas de juros passaram a induzir um maior investimento no setor privado doméstico (Honohan e Walsh, 2002).

Kelly e Everett (2004) atribuem as elevadas taxas de crescimento obtidas pelo país a partir dos anos 1990 a fatores já destacados, tais como: estabilização fiscal, pacto social, IDE, participação na UE e força de trabalho qualificada. Os autores sugerem, porém, um fator adicional: os desenvolvimentos no setor financeiro e as mudanças estruturais que afetaram a oferta e a demanda de crédito. Uma significativa liberalização financeira foi realizada durante os anos 1980 e 1990; depois de anos de baixo crescimento, o crédito ao setor privado passou a aumentar, a partir de 1994, a taxas consideráveis. O amplo financiamento do investimento ajudou a expandir o produto potencial e a sustentar o crescimento não inflacionário da era do "tigre celta".

As mudanças estruturais afetaram tanto a oferta quanto a demanda por crédito. Do lado da oferta, importantes passos foram dados a partir dos anos 1980 para eliminar os controles sobre o crédito, capital e taxas de juros, como a abolição de restrições quantitativas sobre o crescimento do crédito; a diminuição das 
taxas de reserva requeridas dos bancos; a progressiva remoção dos controles de capital; a dissolução do "cartel de taxas de juros" legais e tributários para o desenvolvimento de um mercado de seguros não governamental. Além disso, instrumentos de política monetária orientados pelo mercado foram desenvolvidos pelo banco central e a competição nesses mercados foi encorajada. Esse sistema financeiro mais aberto e mais globalmente integrado foi capaz de responder com maior prontidão ao aumento da demanda por crédito (Kelly e Everett, 2004).

Em adição a essas medidas, as mudanças estruturais do lado da oferta foram reforçadas pelo estabelecimento de um ambiente mais competitivo, que serviu para aumentar a disponibilidade do crédito e diminuir seu custo. Os bancos domésticos não somente estavam livres para competir em termos de taxas de juros, como a desregulamentação também encorajou o estabelecimento de novos entrantes. Mudanças estruturais, inovações financeiras e integração produziram um crescimento na elasticidade da oferta de crédito na Irlanda durante os anos 1990. Ao mesmo tempo, a demanda foi estimulada pela perspectiva de taxas de juros permanentemente baixas. Os bancos se tornaram aptos a utilizar recursos externos de fundos para superar os constrangimentos domésticos em atender à demanda por empréstimos. Tal processo permitiu que os bancos respondessem de maneira flexível e eficiente à demanda por créditos da economia em rápida ascendência. $\mathrm{O}$ crédito foi direcionado principalmente para os setores relativamente mais importantes em termos de criação de emprego, o que, por conseguinte, auxiliou na manutenção de um forte crescimento econômico geral (Kelly e Everett, 2004).

\section{RESULTADOS, PERSPECTIVAS E PROBLEMAS POTENCIAIS}

$\mathrm{Na}$ avaliação de Ó Gráda (2002), uma perspectiva de mais longo prazo, mais histórica, sugere uma interpretação menos otimista da história recente de crescimento econômico na Irlanda. Na sua visão, ao se comparar o desempenho da economia irlandesa com os países "convergentes" da OCDE entre a metade do século e ao final dos anos 1990 verifica-se que, na realidade, o rápido crescimento no último período refletiu o movimento que o país realizava para finalmente conseguir alcançar os demais. Porém, se é verdade que inicialmente a economia irlandesa encontrava-se bastante atrasada em relação a diversas economias européias, não é menos certo que, atualmente, o país encontra-se bastante acima da média da UE em diversos indicadores, como salientado anteriormente.

O bom desempenho da economia irlandesa teria sido ainda acompanhado de alguns problemas: conforme a infra-estrutura se tornava mais pressionada, os pro-

\footnotetext{
${ }^{1}$ A desregulamentação, além de oferecer aos bancos domésticos a liberdade de concorrer entre si em termos de taxas de juros cobradas, ainda facilitou a entrada de novos competidores, gerando um impacto significativo sobre a concorrência no mercado hipotecário no país.
} 
blemas ambientais foram evidenciados, e alguns grupos sociais foram sendo crescentemente marginalizados. Em relação aos problemas de infra-estrutura, destacam-se os setores de energia elétrica e telecomunicações, marcados por ausência de competição e, no caso do setor elétrico, pela ameaça de que a demanda ultrapasse a capacidade geradora do setor nos próximos anos. Especificamente em relação aos níveis de pobreza, McCarthy (2001) indica que houve uma queda considerável em termos absolutos, mas uma análise em termos relativos indica uma piora das classes menos favorecidas, que tendem a ser compostas pelos desempregados (sobretudo trabalhadores menos qualificados), os inválidos e os aposentados.

McCarthy (2001) questiona também a sustentabilidade do crescimento irlandês, na medida em que credita boa parte do êxito da experiência do país a fatores externos. Os riscos relacionados à continuidade do ciclo virtuoso incluiriam, então, um declínio dos recursos da UE, uma queda na demanda global por exportações e uma queda no investimento por parte das multinacionais. Com relação às perspectivas futuras, Ó Gráda (2002), por sua vez, indica que a Irlanda, por ser uma pequena economia aberta - embora bem-sucedida - sofre tanto a ameaça de uma recessão norte-americana como do aumento da competitividade dos países do Leste Europeu, o que poderia desviar os IDEs. A periferia sulina européia, assim como os potenciais futuros membros da UE, apresentariam vantagens de custos, além de possuírem um capital humano considerável, boa infra-estrutura física, e de estarem próximos aos principais mercados da Europa.

\section{REFERÊNCIAS BIBLIOGRÁFICAS}

Bradley, J. e Barry, F. (1997) FDI and trade : the Irish host-country experience, Economic Journal, vol. 107, no. 445, November, pp. 1798-1811.

Doyle, E. (2001) Export-output causality and the role of exports in Irish growth: 1950-1997, International Economic Journal, vol. 15, n 3, Autumn, pp. 1-24.

Kelly, J. e Everett, M. (2004) Financial liberalization and economic growth in Ireland, Quarterly Bulletin, Central Bank, Autumn, pp. 91-112.

McCarthy, F. D. (2001) Social policy and macroeconomics - the irish experience, Policy Research Working Paper 2736, World Bank, December.

Ó Gráda, C. (2002) Is the Celtic Tiger a Paper Tiger? Centre for Economic Research Working Paper, University College Dublin.

Walsh, B. e Honohan, P. (2002) Catching up with the leaders: the Irish hare, Brookings Papers on Economic Activity, 1, pp. 1-77. 